\title{
Evaluation of candidate markers for the peritubular myoid cell lineage in the developing mouse testis
}

\author{
Angela Jeanes, Dagmar Wilhelm, Megan J Wilson, Josephine Bowles, Peter J McClive ${ }^{1}$, \\ Andrew H Sinclair ${ }^{1}$ and Peter Koopman \\ Institute for Molecular Bioscience, The University of Queensland, Brisbane, Queensland 4072, Australia and \\ ${ }^{1}$ Department of Paediatrics, University of Melbourne and Murdoch Children's Research Institute, Royal Children's \\ Hospital, Melbourne, Victoria, Australia
}

Correspondence should be addressed to P Koopman; Email: p.koopman@imb.uq.edu.au

\begin{abstract}
Despite the importance of peritubular myoid (PM) cells in the histogenesis of the fetal testis, understanding the origin and function of these cells has been hampered by the lack of suitable markers. The current study was aimed at identifying molecular markers for PM cells during the early stages of testis development in the mouse embryo. Expression of candidate marker genes was tested by section in situ hybridisation, in some instances followed by immunofluorescent detection of protein products. Collagen type-I, inhibin $\beta A$, caldesmon 1 and tropomyosin 1 were found to be expressed by early-stage PM cells. These markers were also expressed in subsets of interstitial cells, most likely reflecting their common embryological provenance from migrating mesonephric cells. Although not strictly specific for PM cells, these markers are likely to be useful in studying the biology of early PM cells in the fetal testis.

Reproduction (2005) 130 509-516
\end{abstract}

\section{Introduction}

In mammals, the gonads first develop as bipotential organs, the genital ridges, and expression of Sry initiates development of the testes rather than ovaries in the XY individual (Gubbay et al. 1990, Koopman et al. 1991). Many molecular and cellular events occur downstream of Sry that promote the differentiation of the testes. These include proliferation of cells on the gonadal surface, referred to as the coelomic epithelium (Schmahl et al. 2000), the migration of cells from the adjacent mesonephros (Capel et al. 1999), the formation of distinct vasculature (Brennan et al. 2002) and the elaboration of sex cords (Martineau et al. 1997).

Sex cords begin to form around 12.0 days post coitum $(\mathrm{dpc})$ in the mouse, dividing the testis into two compartments. The interstitial compartment surrounding the sex cords is the site of steroid hormone synthesis and the formation of vasculature. The sex cords themselves comprise primordial germ cells that will develop into sperm, Sertoli cells that interact with the germ cells throughout their development, and a surrounding layer of peritubular myoid (PM) cells. Although the sex cords serve primarily to nurture sperm production and ultimately provide a means for sperm export from the testis, their initial formation surprisingly does not depend on the presence of germ cells in the nascent testis: dominant white-spotting (W) mutant embryos in which a c-Kit mutation abrogates the migration of the germ cells into the gonads, develop somatically normal sex cords (Buehr et al. 1993b).

An understanding of the contribution of Sertoli cells to gonadal development has relied on the use of several molecular markers, particularly Sry (Albrecht \& Eicher 2001), Sox9 (Kent et al. 1996) and Amh (Münsterberg and LovellBadge 1991, Hacker et al. 1995). There is strong evidence that pre-Sertoli cells arise from a population of somatic cells originating at the coelomic epithelium (Karl \& Capel 1998, Albrecht \& Eicher 2001, Bullejos \& Koopman 2001) and that they act as organising centres to direct the differentiation of all other cell types. Although they are essential components of sex cords, Sertoli cells develop independently of cord formation, as evidenced by the use of hedgehog pathway blockers that interrupt cord formation but not expression of Sertoli cell markers such as Sox9 (Yao \& Capel 2002).

PM cells appear to develop from precursors that migrate from the mesonephros shortly after peak expression of Sry (Martineau et al. 1997). Mouse fetal gonadal explant cultures have shown that without a mesonephros, the testis will not form sex cords (Buehr et al. 1993a), demonstrating the importance of migrating mesonephric cells in 
this process. However, the lack of a specific marker has made it difficult to prove conclusively the provenance of the PM cells and study their role in sex cord formation.

In the present study we generated a list of candidate genes that could be evaluated as potential markers of very early PM cells. This list was based on the known characteristics and behaviour of PM cells. For example, PM cells are known to cooperate with Sertoli cells to generate basement membrane (Skinner et al. 1985); Sertoli and PM cells have been shown to contribute different components of this membrane, suggesting that a subset of extracellular matrix molecules and the genes that encode them may be PM cell-specific. Further, in postnatal stages of gonadal development, PM cells have a smooth muscle-like phenotype, raising the possibility that they might express markers of smooth muscle cells (Tripiciano et al. 1998, Campagnolo et al. 2001, Nishino et al. 2001). We also tested several genes found in molecular screens to be male-specific (Bowles et al. 2000, McClive et al. 2003), such as inhibin $\beta A$ (Inhba), caldesmon 1 (Cald1) and tropomyosin 1 (Tpm1) that show a distinctive expression pattern around the edge of the sex cords in wholemount in situ hybridisation (ISH), as would be expected for a gene expressed by PM cells. Our results suggest that early PM cells show a profile of marker expression that largely overlaps with that of other interstitial types, perhaps reflecting their common origin as immigrant cells from the mesonephros.

\section{Materials and Methods}

All experiments involving animal tissue were approved by the Animal Ethics Committee at the University of Queensland.

\section{Mouse lines and preparation of embryo tissue}

Pregnant outbred Swiss Quackenbush mice (Central Animal Breeding House, Pinjarra Hills, Brisbane) were killed by cervical dislocation. Embryos were explanted and staged by hind limb morphology. The sex was determined by PCR for the Y-chromosomal gene Zfy as described (Hogan et al. 1994). Embryos were fixed in 4\% paraformaldehyde in PBS overnight at $4{ }^{\circ} \mathrm{C}$, dehydrated through an ethanol/PBS series, washed in toluene, equilibrated with paraffin wax at $65^{\circ} \mathrm{C}$ and mounted in $100 \%$ paraffin. Alternatively, embryos for cryosectioning were equilibrated in $30 \%$ sucrose/PBS, then 50\% sucrose/OCT mounting medium (TissueTek, Bayer Corp, Pittsburgh, PA, USA), embedded in OCT, frozen on dry ice, and stored at $-80^{\circ} \mathrm{C}$.

\section{ISH probes}

ISH probes were generated by PCR using CDNA from $12.5 \mathrm{dpc}$ mouse gonadal tissue and cloned into the pGEM-Teasy vector (Promega), according to the manufacturer's instructions. The primers used to amplify the genes were: $\operatorname{TrkC}$ (high-affinity receptor for neurotrophin 3 (NT3)) (accession number NM_008746) forward: GCCTGAGGTACGCCTGGAACAT, reverse: CATATGTGTCTGGCTTGTGGCAAT; collagen type-1 (Col1a1) (NM_007742) forward: GCCACCTCAAGAGAAGTCTCAAGA, reverse: GTGCTGTA GGTGAAGCGACTGTT; alpha smooth muscle actin ( $\alpha$ Sma) (NM_007392) forward: CTCCCTGGAGAAGAGCTACGAACT, reverse: GTCACATCTATTCCTGACCACTAGA; desmin (Des) (NM_010043) forward: CACAGCAACAACATGAAGTGCTGTA, reverse: CAGGCTGGGGATGTCCACAAACT; and fibronectin (Fn) (NM_010233) forward: AGATGACTCATGCTTTGACCC, reverse: TGCTGAAGCTGAGAA CATGGC. The ISH probe for Inhba corresponds to nucleotides 453-1272 of accession number BC053527. The ISH probe for Cald1 corresponds to nucleotides 286-892 of EST AV024348. The Tpm1 ISH probe corresponds to nucleotides 721-1404 of NM_024427.

\section{Section ISH (SISH)}

SISH was performed on $12 \mu \mathrm{m}$ sections of frozen, tail somite-staged male embryos as described previously (Schaeren-Wiemers \& Gerfin-Moser 1993) with the following modifications: after hybridisation, slides were treated with $10 \mu \mathrm{g} / \mathrm{ml}$ RNaseA in $50 \mathrm{mM}$ Tris- $\mathrm{HCl}$ (pH 7.5), $150 \mathrm{mM} \mathrm{NaCl}$, to remove remaining unbound probe; immunological detection of anti-digoxigenin antibody was carried out with NBT/BCIP (Roche) according to the manufacturer's instructions; and sections were mounted with Mount-Quick aqueous medium (Daido Sangyo, Tokyo, Japan).

\section{Section immunofluorescence}

Immunofluorescence was carried out on either $8 \mu \mathrm{m}$ paraffin sections dried at room temperature overnight, or $12 \mu \mathrm{m}$ cryosections, dried at room temperature for $2 \mathrm{~h}$.

\section{Paraffin immunofluorescence}

Slides were dewaxed by two $10 \mathrm{~min}$ washes in xylene, re-hydrated and boiled for 3 min in Antigen Unmasking Solution (Vector Laboratories), then incubated at room temperature for $20 \mathrm{~min}$. The slides were washed for $10 \mathrm{~min}$ in water and $10 \mathrm{~min}$ in $0.1 \%$ Triton-X in PBS $\left(\mathrm{PBTx}{ }^{0.1 \%}\right.$ ). Subsequent steps were performed as for cryosection immunofluorescence.

\section{Cryosection immunofluorescence}

Slides were washed three times in PBTx ${ }^{0.1 \%}$ for 5 min and blocked for $1-2 \mathrm{~h}$ at room temperature in blocking buffer $\left(10 \%\right.$ heat-inactivated sheep serum in PBTx $\left.{ }^{0.1 \%}\right)$. The sections were incubated with the respective primary antibody dilution in blocking buffer at $4{ }^{\circ} \mathrm{C}$ overnight. Antibodies were removed with three washes in $\mathrm{PBT}{ }^{0.1 \%}$, and slides re-blocked for $1-2 \mathrm{~h}$ at room temperature. Secondary antibodies were incubated at room temperature for $2 \mathrm{~h}$. 
The secondary antibodies were removed with three PBS washes before mounting with a $60 \%$ glycerol/PBS solution. Primary antibodies used were: anti-p75/neurotrophin receptor (NTR) (Chemicon), 1:400; anti-platelet endothelial cell adhesion molecule-1 (PECAM-1) (Pharminogen), 1:300; anti-TPM1 (gift from P Gunning, The Children's Hospital at Westmead, Parramatta, NSW, Australia), 1:250; and anti-steroidogenic factor-1 (SF-1) (gift from K-I Morohashi, National Institute for Basic Biology, Okazaki, Japan), 1:200. Secondary antibodies used were: goat antirabbit Alexa Fluor 594, donkey anti-rat Alexa Fluor 488, goat anti-mouse Alexa Fluor 594, and goat anti-rabbit Alexa Fluor 488 (Molecular Probes), all used at 1:200.

\section{Image capture}

H\&E images were captured on an Olympus IX-70 inverted microscope with a Spot digital camera and Spot version 3.2.6 software. SISH images were captured with a Leica DM6000B compound microscope and Leica DC500 digital camera with Image Manager IM1000 software. Immunofluorescence images were captured with a Bio-Rad Radiance 2000 MP confocal microscope using Lasersharp 2000 software.

\section{Results}

In the past, the identification of PM cells in the mouse embryonic testis has been based on the characteristic flattened morphology they acquire when they have assembled into sex cords by $13.5 \mathrm{dpc}$ (Fig. $1 \mathrm{~A}$ and C). In order to find a molecular marker with which to identify PM cells prior to this time point, and to study their role in the early development of testes, we evaluated a number of candidates suggested by the assumed origin, properties and behaviour of PM cells at different developmental stages.

\section{Candidates relating to cell migration}

Sandwich organ culture experiments have alluded to the presence of a chemoattractant that diffuses from the nascent testis to induce immigration of cells from the mesonephros (Martineau et al. 1997, Tilmann \& Capel 1999). If PM precursor cells were part of this migrating cell population, they would be expected to express the receptor for such a chemoattractant. Previous studies have identified p75/NTR, the low-affinity receptor tyrosine kinase for the nerve growth factor family, as a marker of migrating mesonephric cells (Campagnolo et al. 2001).

We found that PM cells express p75/NTR at $13.5 \mathrm{dpc}$ (Fig. 1B and D). However, the expression was not restricted to PM cells, labelling also vascular endothelial cells identified by expression of the marker PECAM-1 (Fig. 1B and D). These cells have been shown to migrate into the gonad from the adjacent mesonephros. The observed pattern of staining suggests that p75/NTR is an effective marker for migrating mesonephric cells, but is not specific for PM precursor cells.

Further studies have examined the effects of NT3 and its high-affinity receptor TRKC on the morphogenesis of the developing gonad. Beads containing NT3 induced the migration of mesonephric cells into the ovary, suggesting that cells in the mesonephros express the receptor TRKC (Cupp et al. 2003). To test whether TrkC expression is specific for PM precursor cells, we performed SISH on $13.5 \mathrm{dpc}$ mouse embryos. As expected (Tessarollo et al. 1993), we detected TrkC in the central nervous system (Fig. 2E and F); however, no specific signal for TrkC could be detected in $13.5 \mathrm{dpc}$ testis (Fig. 2C and D) above that obtained using a sense RNA probe as control (Fig. 2A and B). It is possible that expression of the receptor is downregulated immediately after immigrant mesonephric cells enter the gonads, and can no longer be detected by
$H \& E$
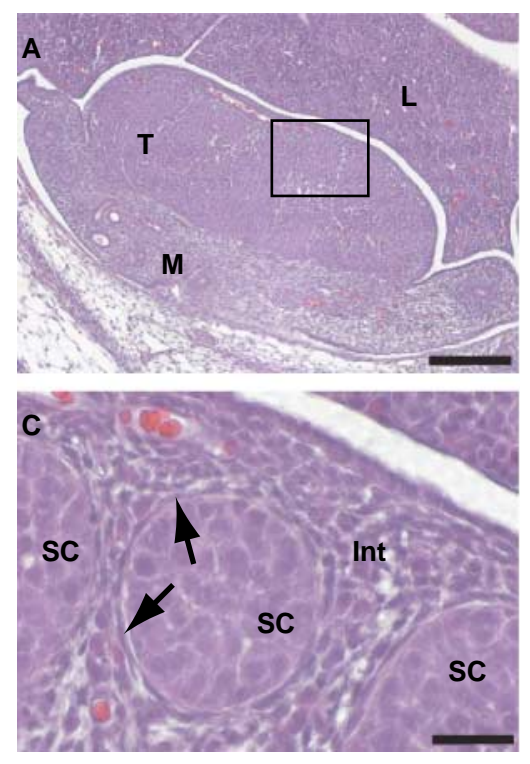

p75/NTR / PECAM-1
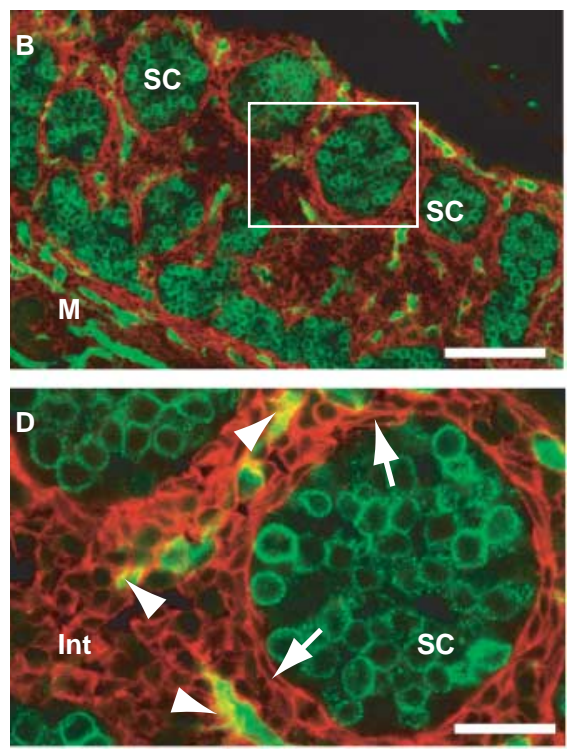

Figure 1 Flattened morphology and expression of p75/NTR in PM cells. (A, C) H\&E staining of a $13.5 \mathrm{dpc}$ mouse embryo section shows flattened PM cells (arrows) at the periphery of a sex cord (SC). (B, D) Immunofluorescence staining of $13.5 \mathrm{dpc}$ mouse embryo section using antibodies to PECAM-1 (green) and p75/NTR (red). Arrows indicate PM cells at the periphery of the sex cord, with positive staining for p75/NTR. Cells expressing both p75/NTR and PECAM-1 are thought to be endothelial cells (arrowheads; yellow). T, testis; M, mesonephros; $\mathrm{L}$, liver; SC, sex cord; Int, interstitium. Rectangles in (A, B) are shown enlarged in $(C, D)$. Scale bar $=200 \mu \mathrm{m}(\mathrm{A}), 100 \mu \mathrm{m}(\mathrm{B}), 33 \mu \mathrm{m}$ (C, D). 

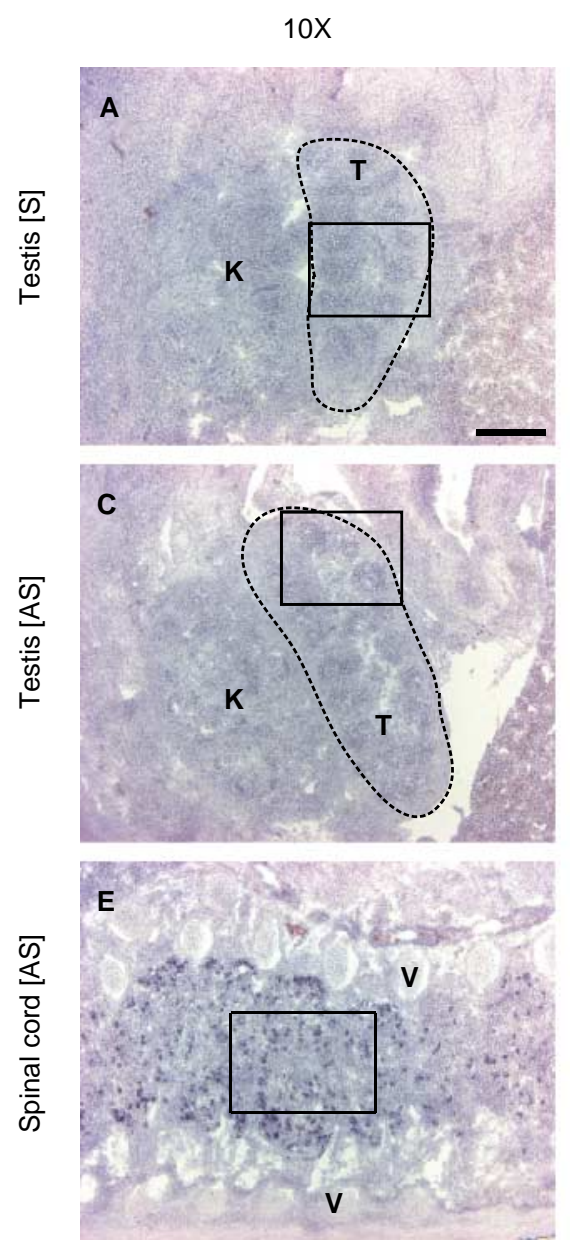

$40 \mathrm{X}$
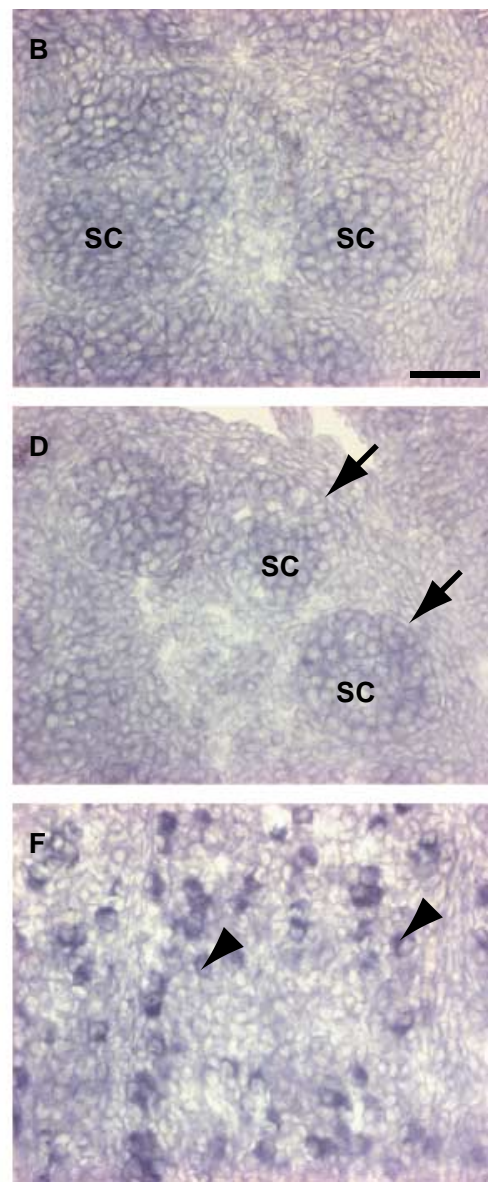

Figure 2 The high-affinity receptor for NT3, TrkC, is not expressed in PM cells at $13.5 \mathrm{dpc}$. In situ hybridisations showing (A, B) TrkC sense control on a $13.5 \mathrm{dpc} X Y$ embryo cryosection shows no specific signal, as expected. (C, D) TrkC antisense probe shows no specific signal, with no staining of PM cells (arrows). (E, F) Positive control showing specific staining of cells of the spinal cord (arrowheads). $[S]$, sense probe; $[\mathrm{AS}]$ antisense probe. $\mathrm{T}$, testis; K, kidney; SC, sex cord; $\mathrm{V}$, vertebra. Rectangles in $(\mathrm{A}, \mathrm{C}, \mathrm{E})$ are shown enlarged in $(\mathrm{B}, \mathrm{D}, \mathrm{F})$. Scale bar $=200 \mu \mathrm{m}(\mathrm{A}, \mathrm{C}, \mathrm{E}), 50 \mu \mathrm{m}(\mathrm{B}, \mathrm{D}, \mathrm{F})$.
13.5 dpc. Alternatively, it may be that the NT3/TRKC signalling pathway does not function in vivo to induce PM cell migration.

\section{Candidates relating to basement membrane production in the sex cords}

An important component of the sex cords is the basement membrane formed by, and between, Sertoli and PM cells. Studies with adult primary cell cultures have shown that monocultures of Sertoli or PM cells differentially express specific extracellular matrix components (Skinner et al. 1985). Of these, only PM cells expressed Fn and Col1a1, indicating that these genes might be useful as PM cell markers in the embryonic stages of gonadal development in vivo, and prompting their inclusion in this study.

At $12.5 \mathrm{dpc}$, Col1a1 expression could be seen in the mesonephros but not in the gonad (Fig. 3A and B). By 13.5 dpc, Col1a1 expression was detected in the mesonephros as well as the interstitium and PM cells of the gonad (Fig. 3C and D). This indicates that Col1a1 expression is up-regulated in the testis between 12.5 and $13.5 \mathrm{dpc}$, coinciding with the time when PM precursors begin to interact with Sertoli cells to produce the basement membrane components.
The expression pattern of $F n$ was found to be dynamic with respect to its cell type specificity. At $13.5 \mathrm{dpc}$, Fn expression was confined to the germ cells inside the sex cords (Fig. 3E and F). By 15.5 dpc, Fn expression subsided in the germ cells possibly as a delayed response to withdrawal from the cell cycle between 12.5 and 13.5 dpc. Fn was up-regulated in cells in the interstitial space and in PM cells (Fig. 3G and $\mathrm{H}$ ). These results identified $F n$ as a possible marker for PM cells at stages of testis development from 15.5 dpc onwards.

\section{Candidates relating to smooth muscle-like phenotype}

In postnatal stages of gonadal development, PM cells develop a smooth muscle-like phenotype, expressing smooth muscle markers $\alpha$ Sma (Palombi et al. 1992) and Des (Virtanen et al. 1986), and contracting in vitro after exposure to prostaglandin $F_{2 \alpha}$ (Tripiciano et al. 1998). However, it is not known when PM cells start to express these markers.

In order to identify the onset of $\alpha S m a$ and Des expression, we performed SISH of mouse embryos at different stages. While there was no expression of Des in the XY gonad at $13.5 \mathrm{dpc}$ (Fig. 4A and B) or $14.5 \mathrm{dpc}$ (data not shown), $\alpha$ Sma expression was seen in a distinct pattern around the edge of the $X Y$ gonad, but not the $X X$ 

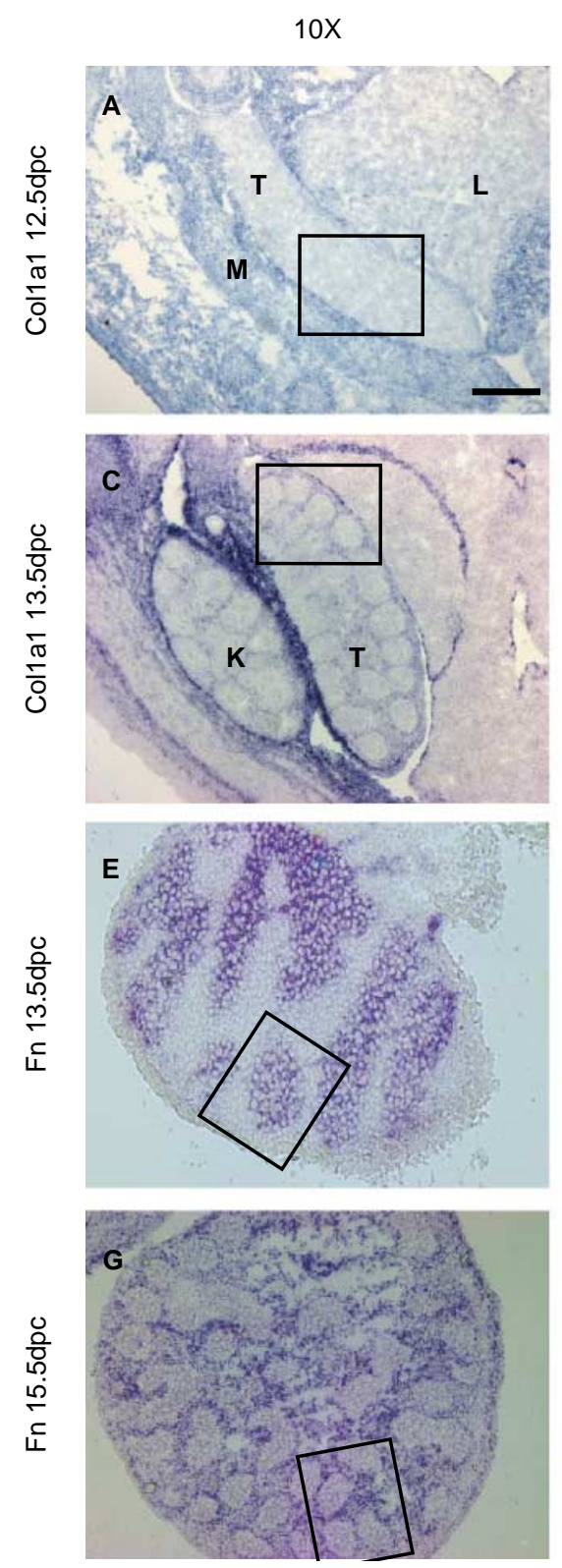

$40 X$
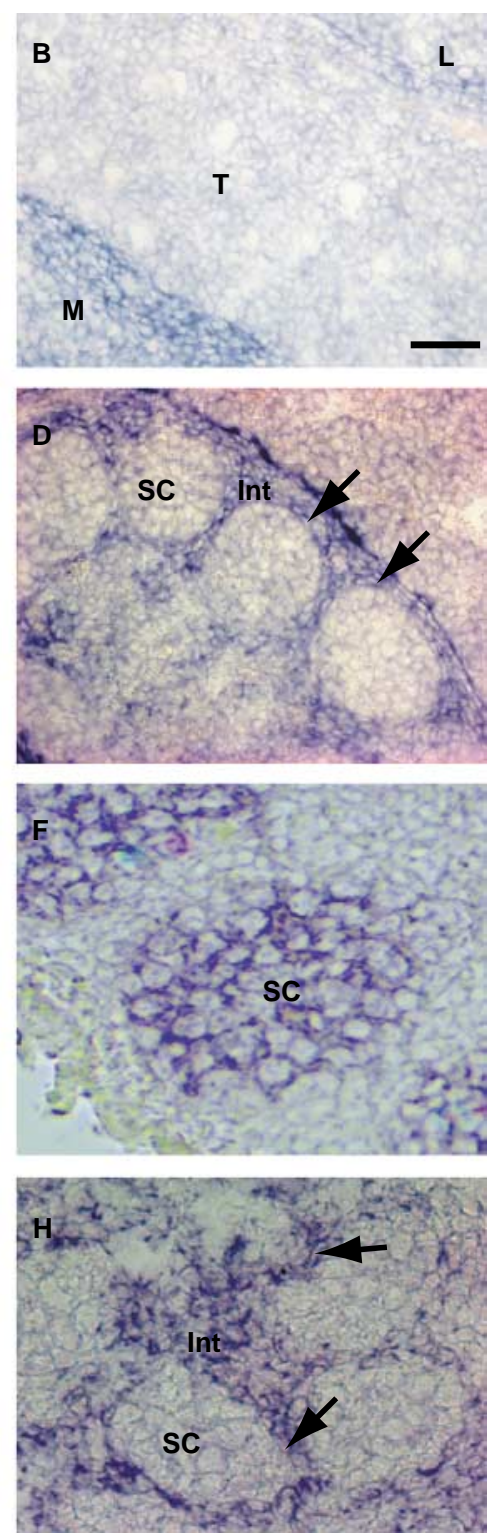

Figure 3 Genes encoding extracellular matrix proteins are expressed by PM cells. In situ hybridisations showing Col1a1 expression in the mesonephros, but not the gonad, of a $12.5 \mathrm{dpc} X Y$ embryo (A, B). By $13.5 \mathrm{dpc}$, Col1a1 is expressed in the PM cells (arrows) and cells of the interstitium (Int) (C, D). At $13.5 \mathrm{dpc}, F n$ is expressed in the germ cells within the sex cords $(\mathrm{SC})(\mathrm{E}, \mathrm{F})$, whereas at $15.5 \mathrm{dpc}(\mathrm{G}, \mathrm{H})$, Fn expression can be seen in PM cells (arrows) and cells of the interstitium (Int). $\mathrm{T}$, testis; $\mathrm{M}$, mesonephros; L, liver; $\mathrm{K}$, kidney; $\mathrm{SC}$, sex cord; Int, interstitium. Rectangles in (A, C, E, G) are shown enlarged in $(B, D, F, H)$. Scale bar $=200 \mu \mathrm{m}(\mathrm{A}, \mathrm{C}, \mathrm{E}, \mathrm{G}), 50 \mu \mathrm{m}(\mathrm{B}, \mathrm{D}, \mathrm{F}, \mathrm{H})$. gonad, at both $13.5 \mathrm{dpc}$ (data not shown) and $14.5 \mathrm{dpc}$ (Fig. 4C and D), and in the mesonephric tubules (Fig. 4D). This reflected expression in the tunica albuginea, a smooth muscle sheath that covers the testis but not the ovary (Karl \& Capel 1998), at similar levels to the staining seen in positive control smooth muscle tissue such as in the lining of the small intestine (Fig. 4F). This contrasted with the negative control, hybridised with sense RNA probe, which showed no specific signal (Fig. 4E). The absence of Des and $\alpha$ Sma expression in PM cells at 13.5 and $14.5 \mathrm{dpc}$ suggests that they do not acquire a smooth muscle-like molecular phenotype until a later stage of testis development.

\section{Candidates arising from expression screens}

Molecular screens have identified several genes that are male-specifically expressed during mouse gonadal development and show a characteristic expression pattern around the sex cords that might result from specific expression in PM cells (Bowles et al. 2000, McClive et al. 2003). These genes, Inhba, Cald1 and Tpm1, were tested by SISH to identify the cells that express these genes. Both Inhba (Fig. 5A and B) and Cald1 (Fig. 5C and D) expression was localised to PM cells and cells of the interstitium. The third candidate, Tpm1, was examined at the mRNA (Fig. 5E and F) and protein (Fig. 5G and H) level, and in both cases was detected in PM and other interstitial cells.

\section{Discussion}

Understanding the biology of any cell type in vivo relies, in part, on having reliable visualisation tools. A robust cell 


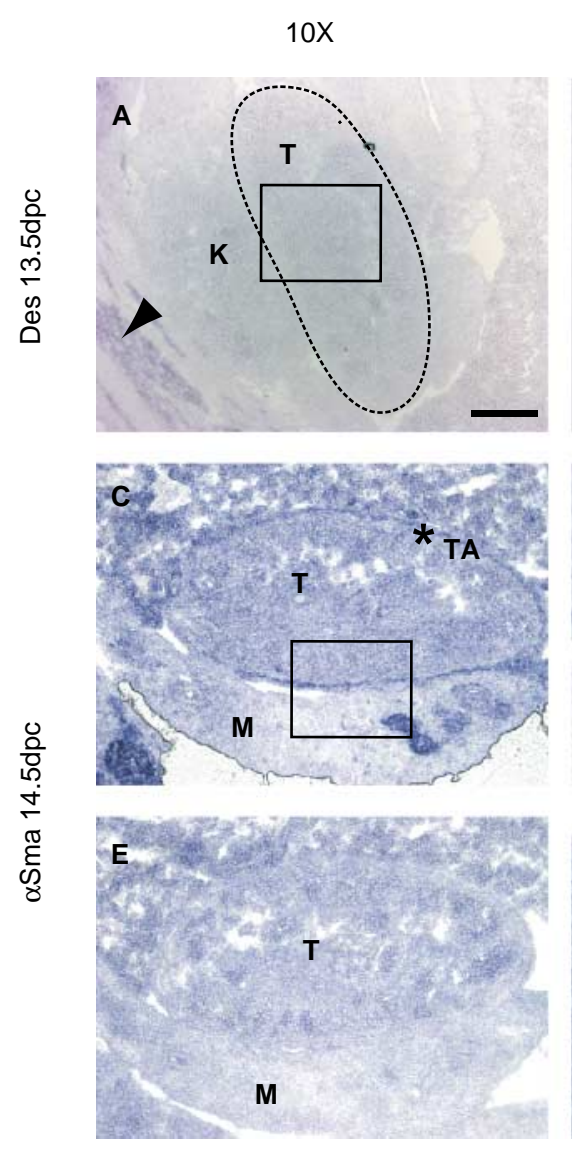

$40 X$
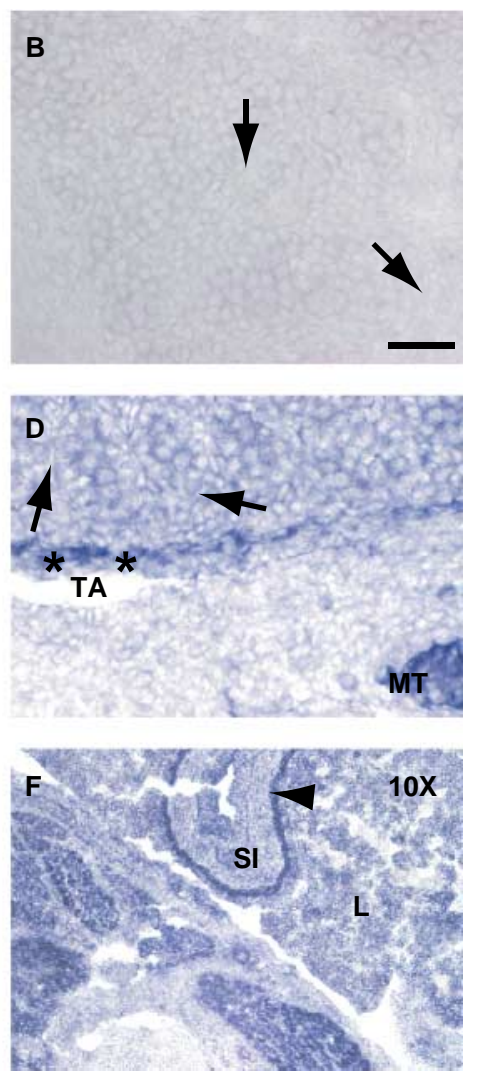

Figure 4 Expression of smooth-muscle markers $\alpha S m a$ and Des at $13.5 \mathrm{dpc}$. In situ hybridisations showing (A, B) expression of Des in smooth muscle tissue (arrowhead), but not in PM cells (arrows), at $13.5 \mathrm{dpc}$. (C, D) Expression of $\alpha$ Sma at the periphery of the testis in the tunica albuginea (TA; asterisk). PM cells (arrows) lacked $\alpha$ Sma expression. (E) Sense control probe for $\alpha$ Sma showing no specific signal. (F) Positive control smooth muscle tissue in the lining of the small intestine $(\mathrm{SI})$. T, testis, demarcated with a dotted line in (A); K, kidney; $M$, mesonephros; TA, tunica albuginea; MT, mesonephric tubule; SI, small intestine; $L$, liver. Rectangles in $(\mathrm{A}, \mathrm{C})$ are shown enlarged in $(\mathrm{B}, \mathrm{D})$. Scale bar $200 \mu \mathrm{m}(\mathrm{A}, \mathrm{C}, \mathrm{E}, \mathrm{F}), 50 \mu \mathrm{m}(\mathrm{B}, \mathrm{D})$. marker not only distinguishes between different cell types, but depending on the marker, can also provide information on the developmental state of the cell type. For example, much has been learned about the biology of primordial germ cells and the early development of the Sertoli cell using the markers alkaline phosphatase and anti-Müllerian hormone respectively (Tran et al. 1987, Ginsburg et al. 1990). Without specific markers for PM cells in the early testis, opportunities for study of the role of these cells in testicular development are limited.

The common mesenchymal origin of PM and other interstitial cells from migrating mesonephric cells suggests molecular similarities between all these cell types, complicating the search for a cell type-specific marker. Nevertheless, at some time in gonadal development, the PM lineage will be determined and become distinguishable from the surrounding cells by a unique pattern of gene expression.

At what point does a PM-specific molecular signature arise? The population of migrating mesonephric cells may be pluripotent, with a subset instructed to differentiate as PM cells through interaction with pre-Sertoli cells around $12.0 \mathrm{dpc}$. Alternatively, the migrating mesonephric cells may be pre-determined, in which case the molecular hallmarks of PM cell fate may exist from as early as $11.5 \mathrm{dpc}$, when migration begins. This latter explanation is consistent with the experimental observation that genetically marked migrating mesonephric cells in explant organ cultures have the potential to develop into distinctly different cell types, as judged by morphology and expression of different cell markers (Nishino et al. 2001).

Irrespective of when a PM cell is first determined, the flattened morphology of a PM cell by $13.5 \mathrm{dpc}$, around the edge of the sex cords, phenotypically distinguishes the lineage from the surrounding lineages. It is reasonable to assume that by $13.5 \mathrm{dpc}$, PM cells express a specific gene, or complement of genes, associated with this morphology or with their contribution to basement membrane production in the sex cords.

The present study showed that Col1a1, Inhba, Cald1 and Tpm1 were all expressed in early PM cells, albeit not uniquely. Further investigation may reveal a combination of these markers that is unique to PM cells as distinct from other mesonephros-derived cell types of the early testis. Notably, the anti-TPM1 antibody used in this study recognises isoforms 1, 2, 3 and 6 of this protein (Kee et al. 2004), and the ISH probe is not isoform-specific. It is unclear whether all isoforms are expressed in all TPM1-positive cells, or whether some isoforms are specific to a certain cell type, as has been suggested by other studies examining expression of Tpm1 (Denz et al. 2004). A more complete expression analysis is required with 

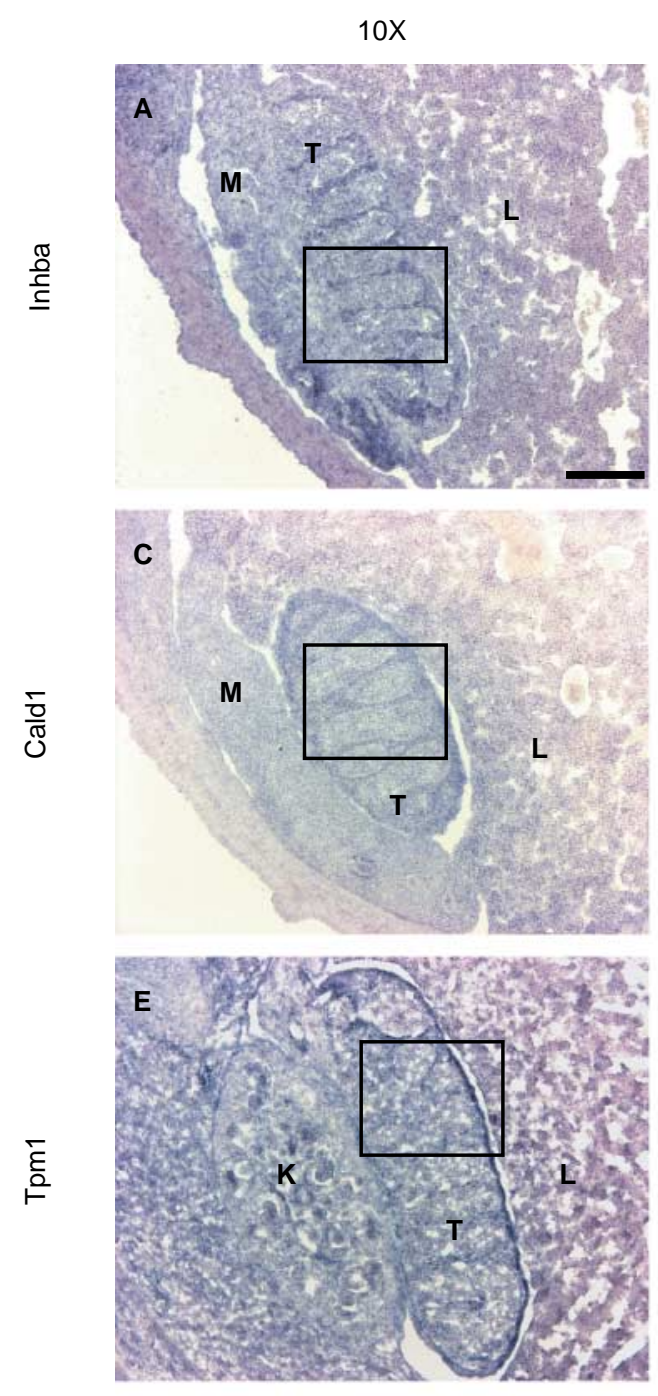

$20 x$
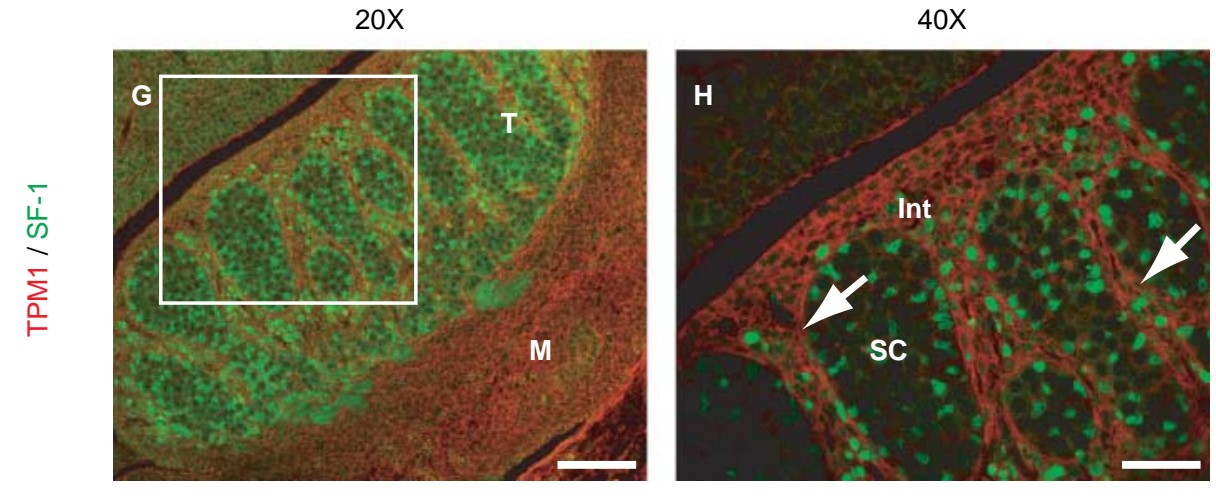

$40 X$
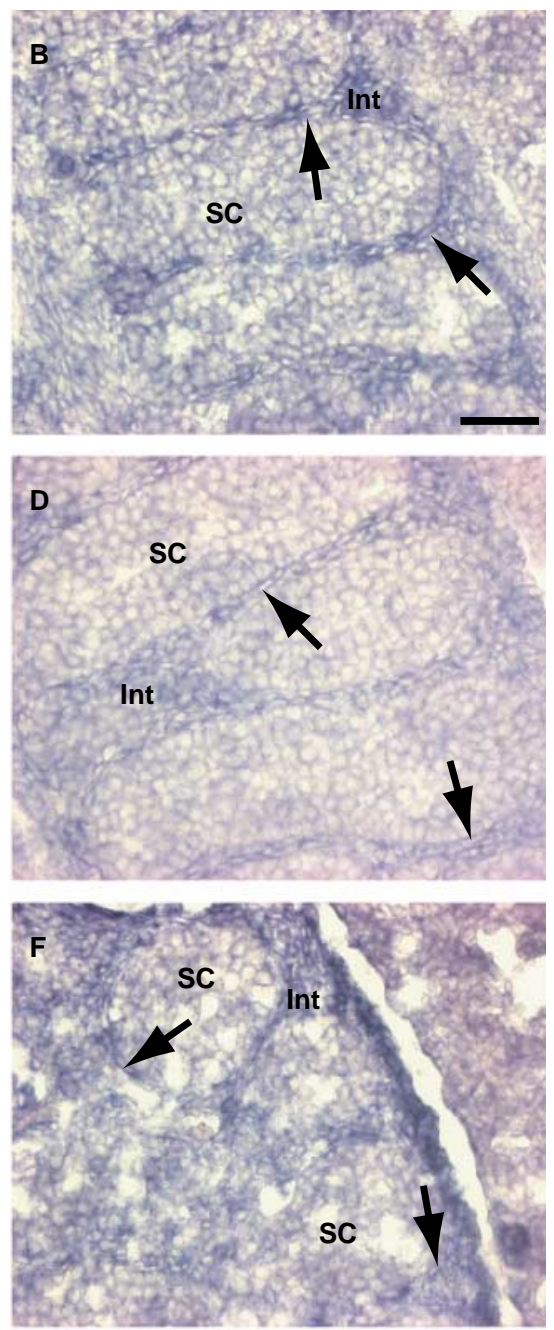

$40 x$

isoform-specific antibodies or ISH probes in order to conclude which isoforms are expressed in which cells.

The expression of Col1a1, Inhba, Cald1 and Tpm1 by some interstitial cells limits the usefulness of these molecules as markers of PM cells, and a marker showing complete cell-type specificity remains an important goal in the field. The extensive lists of genes encountered in various molecular screens (Bowles et al. 2000, Grimmond et al.
Figure 5 Expression at $13.5 \mathrm{dpc}$ of candidates arising from molecular screens. In situ hybridisations showing expression of Inhba (A, B), Cald1 (C, D) and Tpm1 (E, F) in PM cells (arrows) at the edge of the sex cords (SC), as well as in cells of the interstitium (Int). (G, H) TPM1 protein (red) was detected by immunofluorescence in PM cells (arrows) and cells of the interstitium (Int). SF-1 (green) labels the somatic cells (Leydig and Sertoli) of the gonad. T, testis; $M$, mesonephros; L, liver; SC, sex cord; Int, interstitium; $\mathrm{K}$, kidney. Rectangles in (A, C, $E, G)$ are shown enlarged in $(B, D, F$, H). Scale bar $=200 \mu \mathrm{m}$ (A, C, E), $100 \mu \mathrm{m}(\mathrm{G}), 50 \mu \mathrm{m}(\mathrm{B}, \mathrm{D}, \mathrm{F}, \mathrm{H})$.
2000, Wertz \& Herrmann 2000, Menke \& Page 2002, McClive et al. 2003) may provide additional candidates for such studies. Alternatively, potential chemoattractant receptors involved in signalling pathways other than the NT3/TRKC pathway may yield a marker specific for migrating PM cells in vivo. In the interim, genes found in this study to be expressed by PM cells may provide an avenue for further investigation into PM cell biology. 


\section{Acknowledgements}

We thank Deon Knight and Tanya Hurley for access to wholemount in situ hybridisation data. The anti-TPM1 and anti-SF-1/Ad4BP antibodies were kind gifts from P Gunning and K-I Morohashi respectively. This work was funded by grants from the Australian Research Council (ARC) and National Health and Medical Research Council (NHMRC) of Australia. P K is an ARC Professorial Research Fellow. P K and $\mathrm{A} \mathrm{H} \mathrm{S}$ are members of the ARC Centre of Excellence in Biotechnology and Development. The authors declare that there is no conflict of interest that would prejudice the impartiality of this scientific work.

\section{References}

Albrecht KH \& Eicher EM 2001 Evidence that Sry is expressed in preSertoli cells and Sertoli and granulosa cells have a common precursor. Developmental Biology $24092-107$.

Bowles J, Bullejos M \& Koopman P 2000 A subtractive gene expression screen suggests a role for vanin-1 in testis development in mice. Genesis 27 124-135.

Brennan J, Karl J \& Capel B 2002 Divergent vascular mechanisms downstream of Sry establish the arterial system in the XY gonad. Developmental Biology 244 418-428.

Buehr M, Gu S \& McLaren A 1993a Mesonephric contribution to testis differentiation in the fetal mouse. Development 117 273-281.

Buehr M, McLaren A, Bartley A \& Darling S 1993b Proliferation and migration of primordial germ cells in We/We mouse embryos. Developmental Dynamics 198 182-189.

Bullejos M \& Koopman P 2001 Spatially dynamic expression of Sry in mouse genital ridges. Developmental Dynamics 221 201-205.

Campagnolo L, Russo MA, Puglianiello A, Favale A \& Siracusa G 2001 Mesenchymal cell precursors of peritubular smooth muscle cells of the mouse testis can be identified by the presence of the p75 neurotrophin receptor. Biology of Reproduction 64 464-472.

Capel B, Albrecht KH, Washburn LL \& Eicher EM 1999 Migration of mesonephric cells into the mammalian gonad depends on Sry. Mechanisms of Development 84 127-131.

Cupp AS, Uzumcu M \& Skinner MK 2003 Chemotactic role of neurotropin 3 in the embryonic testis that facilitates male sex determination. Biology of Reproduction 68 2033-2037.

Denz CR, Narshi A, Zajdel RW \& Dube DK 2004 Expression of a novel cardiac-specific tropomyosin isoform in humans. Biochemical and Biophysical Research Communications 320 1291-1297.

Ginsburg M, Snow MH \& McLaren A 1990 Primordial germ cells in the mouse embryo during gastrulation. Development 110 521-528.

Grimmond S, Van Hateren N, Siggers P, Arkell R, Larder R, Soares MB, Bonaldo MD, Smith L, Tymowska-Lalanne Z, Wells C \& Greenfield A 2000 Sexually dimorphic expression of protease nexin- 1 and vanin- 1 in the developing mouse gonad prior to overt differentiation suggests a role in mammalian sexual development. Human Molecular Genetics 9 1553-1560.

Gubbay J, Collignon J, Koopman P, Capel B, Economou A, Münsterberg A, Vivan N, Goodfellow P \& Lovell-Badge R 1990 A gene mapping to the sex-determining region of the mouse $Y$ chromosome is a member of a novel family of embryonically expressed genes. Nature 346 245-250.

Hacker A, Capel B, Goodfellow P \& Lovell-Badge R 1995 Expression of Sry, the mouse sex determining gene. Development 121 $1603-1614$.

Hogan B, Beddington R, Costantini F \& Lacy E 1994 Manipulating the Mouse Embryo: a Laboratory Manual, edn 2. New York: Cold Spring Harbor Laboratory Press.

Karl J \& Capel B 1998 Sertoli cells of the mouse testis originate from the coelomic epithelium. Developmental Biology 203 323-333.
Kee AJ, Schevzov G, Nair-Shalliker V, Robinson CS, Vrhovski B \& Ghoddusi M, Qiu MR, Lin JJ, Weinbergen R, Gunning PW \& Hardeman EC 2004 Sorting of a nonmuscle tropomyosin to a novel cytoskeletal compartment in skeletal muscle results in muscular dystrophy. Journal of Cell Biology 166 685-696.

Kent J, Wheatley SC, Andrews JE, Sinclair AH \& Koopman P 1996 A male-specific role for SOX9 in vertebrate sex determination. Development 122 2813-2822.

Koopman P, Gubbay J, Vivian N, Goodfellow P \& Lovell-Badge R 1991 Male development of chromosomally female mice transgenic for Sry. Nature 351 117-121.

Martineau J, Nordqvist K, Tilmann C, Lovell-Badge R \& Capel B 1997 Male-specific cell migration into the developing gonad. Current Biology 7 958-968.

McClive PJ, Hurley TM, Sarraj MA, van den Bergen JA \& Sinclair AH 2003 Subtractive hybridisation screen identifies sexually dimorphic gene expression in the embryonic mouse gonad. Genesis 37 84-90.

Menke DB \& Page DC 2002 Sexually dimorphic gene expression in the developing mouse gonad. Gene Expression Patterns 2 359-367.

Münsterberg A \& Lovell-Badge R 1991 Expression of the mouse antiMüllerian hormone gene suggests a role in both female and male sexual differentiation. Development 113 613-624.

Nishino K, Yamanouchi K, Naito K \& Tojo H 2001 Characterization of mesonephric cells that migrate into the $\mathrm{XY}$ gonad during testis differentiation. Experimental Cell Research 267 225-232.

Palombi F, Farini D, Salanova M, de Grossi S \& Stefanini M 1992 Development and cytodifferentiation of peritubular myoid cells in the rat testis. Anatomical Record 233 32-40.

Schaeren-Wiemers N \& Gerfin-Moser A 1993 A single protocol to detect transcripts of various types and expression levels in neural tissue and cultured cells: in situ hybridization using digoxigeninlabelled cRNA probes. Histochemistry $100431-440$.

Schmahl J, Eicher EM, Washburn LL \& Capel B 2000 Sry induces cell proliferation in the mouse gonad. Development 127 65-73.

Skinner MK, Tung PS \& Fritz IB 1985 Cooperativity between Sertoli cells and testicular peritubular cells in the production and deposition of extracellular matrix components. Journal of Cell Biology $1001941-1947$.

Tessarollo L, Tsoulfas P, Martin-Zanca D, Gilbert DJ, Jenkins NA, Copeland NG \& Paruda LF 1993 trkC, a receptor for neurotrophin3 , is widely expressed in the developing nervous system and in non-neuronal tissues. Development 118 463-475.

Tilmann C \& Capel B 1999 Mesonephric cell migration induces testis cord formation and Sertoli cell differentiation in the mammalian gonad. Development 126 2883-2890.

Tran D, Picard J-Y, Campargue J \& Josso N 1987 Immunocytochemical detection of Anti-Müllerian hormone in Sertoli cells of various mammalian species including man. Journal of Histochemistry and Cytochemistry 35 733-743.

Tripiciano A, Filippini A, Ballarini F \& Palombi F 1998 Contractile response of peritubular myoid cells to prostaglandin F2alpha. Molecular and Cellular Endocrinology 138 143-150.

Virtanen I, Kallajoki M, Narvanen O, Paranko J, Thornell LE, Miettinen M \& Lehto VP 1986 Peritubular myoid cells of human and rat testis are smooth muscle cells that contain desmin-type intermediate filaments. Anatomical Record 215 10-20.

Wertz K \& Herrmann BG 2000 Large-scale screen for genes involved in gonad development. Mechanisms of Development 98 51-70.

Yao HH \& Capel B 2002 Disruption of testis cords by cyclopamine or forskolin reveals independent cellular pathways in testis organogenesis. Developmental Biology 246 356-365.

Received 4 March 2005

First decision 12 April 2005

Accepted 23 May 2005 